\title{
Can Employee Training and Development Increase Organizational Resilience Against Economic Crises?
}

\author{
Prof. Dr. Saima Tabassum Siddiqui, Ph.D, MS, MBA. \\ Assistant Professor (Business Administration) \\ University of Sindh, Jamshoro, Pakistan
}

\begin{abstract}
Training is valuable for both organization and its employee. Training directly contributes in learning and individual capacity of an employee is enhanced. The trained employee produces better outcomes and thus the organization flourishes and produces more profits. Similarly, the trained employees also perform better in the crises situation and support the organization to reach and adjust for sudden changes responding effectively organizational. This paper examines the relationship of employee training and development as responsibility of human resource management and its contribution in the organizational resilience. Author's analysis suggests that the training and development of employees is vital for building resilient organization.
\end{abstract}

Keywords: Employee training, organizational resilience, economic crises, human resource management.

\section{INTRODUCTION}

Nowadays, organizations are facing challenges from their physical environment, natural disasters and economic crises. These situations have raised the need for resilient organizations and employees (Ho, Verreyne, \& Galvin, 2014). Economic crisis and natural disasters has across-the-board consequences which infuse all areas of organizational, social and economic life. Generally, financial and economic crisis have adverse impacts on organizations. To be flexible, organizations depend on their leadership and people, a mindfulness and comprehension of their working condition, their capacity to oversee vulnerabilities, and their capacity to adjust considering rapid change. Therefore, human resource is the central asset of an organization and it needs to be developed in terms of skills and knowledge. Trained employees are better able to perform their jobs especially in difficult situations. This article explores the role of employee training and development in enhancing organizational resilience especially against the economic crises.

For this article the organizational resilience is defined as the capacity of an organization to foresee, plan for, react and adjust to incremental change and sudden interruptions keeping in mind the end goal to survive and thrive (BSI Group, 2017). Resilience is a multidimensional, socio-technical phenomenon and depends on skills of individuals or groups to manage instability. Similarly, the term training is characterized as a methodical advancement of learning, aptitudes and states of mind required by employees to perform satisfactorily on a given assignment or employment (Olaniyan \& Ojo, 2008). Development is referred as activities linked with accruing new skills and long term growth (Tahir, Yousafzai, Jan, \& Hashim, 2014).

Primarily, the human resource practitioner only paid attention to the managerial issues raised after the disaster or crisis, for example, employee assistance, insurance and compensation (Wang, Hutchins, \& Garavan, 2009). However, this topic is very significant and broad and need to be explored in detail because the changing landscape of business and increasing man-made and natural disasters constantly pose threats on organizational stability. Many organizations do not prepare for performing in crisis and their human resource department and their leadership assumes that their organization has capability of resilience to bear external shocks.

The study of organizational resilience and crisis management is relatively new in the genera of human resource management. Organizational resilience or crisis management has been a mainly ignored area in human resource development (Wang, Hutchins, \& Garavan, 2009; Ho, Verreyne, \& Galvin, 2014) despite, the increasingly noted effect of organizational crises on the employees and organizational 
performance. However, the role of training and development on the organizational resilience is not studied in a greater detail. Therefore, this article is contributing and adding knowledge by investigating the link between employee training and development for improving organizational resilience.

One of the limitations in this paper is the relatively limited literatures related to the human resource on organizational resilience. Another is the inadequate analysis of training and development in relation to organizational resilience literature.

\section{LITERATURE REVIEW}

Training is an apparatus to help people to contribute and be effective in their role. The reason for the training is to help individuals learn and create abilities to play out their responsibilities adequately and it must outcome in behavior transform. Training is linked with improved job performance and satisfaction which results in development (Tahir, Yousafzai, Jan, \& Hashim, 2014). The organizations get the highest level of commitment and motivation of their employees via training and development. There is positive evidence in the literature on the relationship among training, development and productivity (Olaniyan \& Ojo, 2008). This also contributes in developing organizational resilience.

Organizations respond to instability and unpredictability from multiple points of view; they centralize their internal control systems, they learn, they are innovative, and they adjust (Pfeffer, 1978; Carroll, 1998; Kendra \& Wachtendorf, 2003; Vogus \& Sutcliffe, 2008). The concept of resilience labeled as bouncing back, strength, absorption, surviving and flourishing (Hale, 2006; Tierney, 2003; Berkes, 2007; Seville, 2009).

It necessitates organizations to adapt and to be highly consistent and permits them to manage disruptions. Many researchers have studied the ability to adapt as the skill of resilience. However, the organizational resilience is more than the ability to adapt (Hale \& Heijer, 2006). There are two types of adaptive capacity (Vogus \& Sutcliffe, 2008). First adaptive capacity shows organization's capability of bouncing back using prevailing skills and resources and the second, adaptive capacity is developed when organizations learn new skills to address outside challenges (Woods \& Wreathall, 2008).

Hollnagel, Nemeth, \& Dekker (2008) as categorize a set of four capabilities that they claim define the organizational resilience. These are: the skill to respond in instabilities and threats, the capability to monitor their circumstances, the ability to predict troubles, and the ability to learn from experience (Hollnagel, Nemeth, \& Dekker, 2008).

The ability to learn is one of the most important skill for building organizational resilience (Wang, Hutchins, \& Garavan, 2009) and the human resource practitioner need to pay careful attention to include it in the training and development programme. A business's ability for resilience in any crisis is produced through deliberately overseeing its human capital and developing skills among its employees, that when accumulated at the organizational level, make it workable for associations to accomplish the capacity to react in a strong way when they encounter serious upsets (Wang, Hutchins, and Garavan, 2009).

The link between organizational resilience and efficiency is also highlighted in the literature. It is the goal of human resource management to frequently invest in developing capacities of employees to respond effectively in emergencies and be resilient. Building resilience capacity also provides a competitive advantage for the organization (Parsons, 2007). Therefore, the organizational resilience is considered as a permanent target that is significant for performance during routine and emergency situations (Mitroff, 2005). There is a direct link between organizational resilience and competitiveness. Both the phenomena share similarities. The both prepare the organization to foresee future challenges and share information about the market environment and translate into environmental awareness per its impact on the organization. This trait is like the organizations ability to know its opposition and environment (Wang, Hutchins, \& Garavan, 2009). Consequently, organizations can better prepare their systems and develop skills of their employees to effectively deal in a competitive environment.

\section{ELEMENTS AND CHARACTERISTICS OF RESILIENT INDIVIDUAL AND ORGANIZATIONS}

The three important elements of Organizational Resilience: Product excellence, Process reliability and People behaviors (BSI Group, 2017). The organizational resilience model of BSI (figure 1) presents people and their behaviors as one of the important aspect of the organizational resilience. 


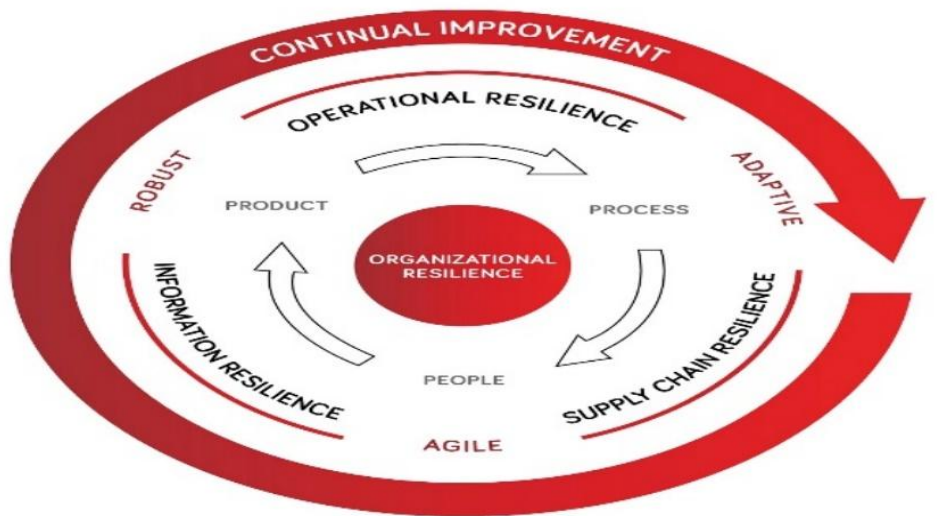

Figure1. Elements of organizational resilience (BSI Group, 2017)

BSI's model is intentionally drawn as a constructive input circle. The effectiveness of the process creates product reliability and connects to the people behavior. This model looks at the continuing resilience which is based on the holistic abilities of the organization for addressing challenges and achieving prosperity (BSI Group, 2017) .

Peoples' behavior plays a vital role in developing organizational resilience. A study was conducted on 40 children to understand resilience. The study recognized four characteristics that differentiate resilient and non-resilient people: problem solving capabilities, satisfactory perceptions, optimistic reinforcement, and strong faith (Werner \& Smith, 2001). The findings of this study demonstrate that resilience is an ability that can be established intentionally. Resilient employees exhibit behaviors like, resourcefulness, and creativity for problem solving.

Several cognitive intellectual factors of employees contribute in creating organizational resilience (Lengnick-Hall, Beck, \& Lengnick-Hall, 2011). These factors could be achieved and imparted through deliberative training and human resource management. The organizations need to develop clear aim, values, and vision that can contribute in the developing a positive and constructive positioning of employees and their roles as assets of the organization. The positive meaningfulness of organizations and their work enables the employees to respond in the crisis with robustness. The common outlook that empowers a firm to push ahead with adaptability is frequently a complicated mix of aptitude, advantage, inventiveness, and conclusiveness despite vulnerability Organizational resilience relies on upon a capacity to conceptualize arrangements that are both novel and proper (Lengnick-Hall, Beck, \& Lengnick-Hall, 2011). Learned resourcefulness, cleverness, and creatively is required to needed to create unconventional responses to unique challenges.

Thirdly, resilience also depends on the development of valuable, repetitive and pragmatic habits that are useful in the first response to an emergency for example, the emergency evacuation drills teach employees on how to react in case of a fire and repetitive drills become habits.

Fourth is behavioral preparedness. It is taking activities and making speculations before they are expected to guarantee that an association can profit by circumstances that rise. Behavioral readiness likewise implies that an association intentionally unlearns out of date data practices and system. At long last, access to expansive asset systems is a key component in making logical conditions that bolster flexibility improvement (Lengnick-Hall, Beck, \& Lengnick-Hall, 2011).

\section{HR SySTEM's Role in ORganizational RESILIENCE AND TRAINING}

The human resource System plays and important role in training and development and building organizational resilience. (Hollnagel, Nemeth, \& Dekker, 2008).

Lengnick-Hall, Beck, \& Lengnick-Hall, 2011 have presented a model as in Figure. 2. The model suggests that the capacity for resilience is directly connected to an organization's Human Resource system. HR principles and desired employee contributions regulate the HR policy formulation. It is also utmost important to define the required employee contribution in times of crisis or desired resilience behavior. Second most important element is the HR principles. Both should be representative of the HR policies. Desired employee contributions more generally aimed on developing component capabilities. Overall the HR system develops the organizational capacity for resilience and desired outcomes. (Lengnick-Hall, Beck, \& Lengnick-Hall, 2011) 


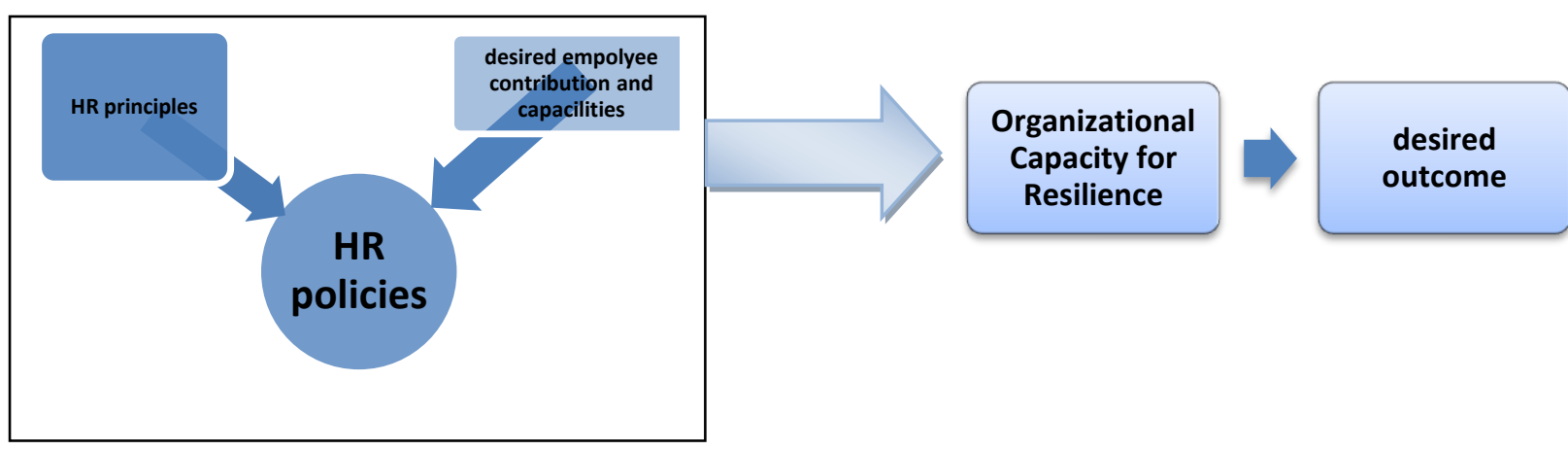

Figure2. Adopted from (Lengnick-Hall, Beck, \& Lengnick-Hall, 2011) Strategic human resource management system in developing a capacity for organizational resilience.

\section{Conclusion}

It is displayed in this paper that organizational resilience has a direct link with employee capacities. Organizational resilience is a learn behavior and training one of the important factor in learning and practices organizational resilience. Training and development is the most important component of any organization for maintaining its productivity, competitiveness and resilience. It is the building block in developing organizational resilience. The human resource experts assume an essential part in understanding the advantages of an association's ability for resilience. It is also clear that the association's ability for resilience is a multilevel aggregate quality rising out of the abilities, activities, and connections of people and units inside the firm. Representative commitments, HR practices, and HR arrangements are the essential incorporating instruments for accomplishing the collective resilience. Since resilience is produced after some time through connections and training therefore, resilience should be developed before any crisis and it should be strengthened through practice and learning from experiences.

\section{REFERENCES}

[1] Berkes, K. (2007). "Understanding uncertainty and reducing vulnerability: Lessons from resilience thinking. Natural Hazards, 283-295.

[2] BSI Group. (2017, April 9). Organizational Resilience. Retrieved from https://www.bsigroup.com/en-GB/our-services/Organizational-Resilience/

[3] Carroll, J. S. (1998). Organisational learning activities in high-hazard industries: The logics underlying self-analysis. Journal of Management Studies, 699-717.

[4] Hale, A., \& Heijer, T. (. (2006). Defining resilience. In e. a. Hollnagel, Resilience engineering concepts and precepts, (pp. 35-40.). Ashgate: Burlington.

[5] Ho, M., Verreyne, M.-L., \& Galvin, P. (2014). Organizational resilience and the challenge for human resource management: Conceptualizations and frameworks for theory and practice. 1-8.

[6] Hollnagel, E., Nemeth, C. P., \& Dekker, S. (2008). Remaining sensitive to the possibility of failure. Cornwall: Ashgate.

[7] Kendra, J. M., \& Wachtendorf, T. (2003). Creativity in emergency response to the World Trade Center disaster." Beyond September 11th: An account of post-disaster research. CO: Natural Hazards Research and Information, Univ. of Colorado.

[8] Lee, A. V., Vargo, J., \& Seville, E. (2013). Developing a Tool to Measure and Compare Organizations' Resilience. NATURAL HAZARDS REVIEW, 29-41.

[9] Lengnick-Hall, C. A., Beck, T. E., \& Lengnick-Hall, M. L. (2011). Human Resource Management Review, 243-255.

[10] Mitroff, I. I. (2005). From my perspective: Lessons from 9/11: Are companies better prepared today? Technol. Forecast. Soc. Change, 375-376.

[11] Olaniyan, D. A., \& Ojo, L. B. (2008). Staff Training and Development: A Vital Tool for Organizational Effectivenes . European Journal of Scientific Research, 326-331.

[12] Parsons, D. (2007, Nov 22). National Organizational Resilience Framework Workshop: the outcomes. Retrieved from National Organizational Resilience Framework Workshop: http://www.tisn.gov.au/Documents/FINAL1Workshop.pdf 
[13] Pfeffer, J. (1978). Organizational design, Arlington: Harlan Davidson, .

[14] Seville, E. (2009). . Resilience: Great concept...but what does it mean for organisations? Wellington,: New Zealand Government, .

[15] Tahir, N., Yousafzai, I., Jan, S. D., \& Hashim, M. (2014). The impact of employee training and development on employee Performance and Productivity. International Journal of Academic Research in Business and Social Sciences, 86-98.

[16] Tierney, K. (2003). Conceptualising and measuring organizational and community resilience: Lessons from the emergency response following the September 11, 2001 attack on the World Trade Center . Neward: Univ. of Delaware.

[17] Vogus, T. J., \& Sutcliffe, K. M. (2008). Organizational resilience: Towards a theory and research agenda. IEEE Int. Conf. on Systems, Man and Cybernetics, . Montreal.

[18] Wang, J., Hutchins, H. M., \& Garavan, T. N. (2009). Exploring the Strategic Role of Human Resource Development in Organizational Crisis Management. Human Resource Development Review, 1-32.

[19] Werner, E. E., \& Smith, R. S. (2001). Journeys from childhood to midlife: Risk, resilience, and recovery. Ithaca, NY: NY: Cornell University Press.

[20] Woods, D., \& Wreathall, J. (2008). Stress-strain plots as a basis for assessing system resilience. In H. e. al, remaining sensitive to the possibility of failure (pp. 143-158). Surrey: Ashgate.

\section{AUTHOR's BIOGRAPHY}

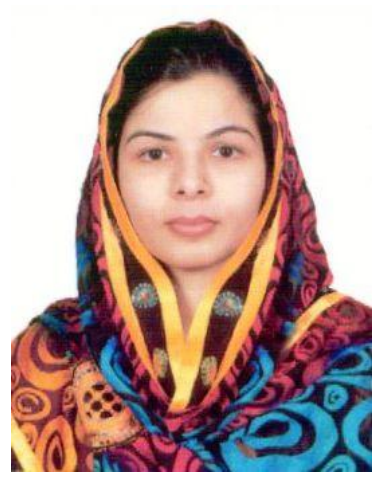

Prof. Dr. Saima Tabassum Siddiqui, started her career as Lecturer (Business Administration) at University of Sindh, Jamshoro, Pakistan in 2007 and presently working there as Assistant Professor (Business Administration). She has 10 plus years' teaching and research experience at University level. She has acquired professional degrees from both public sector and private sector universities recognized worldwide i.e Ph.D (Public Administration) from University of Karachi, Karachi, Pakistan, MS (Business Administration) from Hamdard University, Karachi, Pakistan, MBA (Finance) and BBA (Honours) from Institute of Business Administration, University of Sindh, Jamshoro, Pakistan. 10 research papers are at her credit duly published in International Journals. 